\title{
An Elusive Submucosal Laryngeal Malignancy
}

\author{
${ }^{1}$ Preethy Mary, ${ }^{2}$ Mathew Dominic
}

\section{ABSTRACT}

Submucosal laryngeal tumors, though uncommon, are not rare. Though the symptomatology may suggest a laryngeal malignancy, a routine direct laryngoscopy may not reveal the lesion. Obtaining tissue biopsy may also prove to be a challenge. Radiological modality becomes mandatory in these cases to get a representative biopsy.

The present report describes a case with an unusually high number of negative biopsies. The course of management and related literature are discussed.

Keywords: Submucosal laryngeal malignancy, Biopsy, CT scan. How to cite this article: Mary P, Dominic M. An Elusive Submucosal Laryngeal Malignancy. Int J Phonosurg Laryngol 2014;4(2):71-72.

Source of support: Nil

Conflict of interest: None

\section{INTRODUCTION}

Laryngeal malignancies present early as the leading symptom, hoarseness, are noticed by the patient and his/her relatives at the onset of the disease. Lesions are usually easily visible on endoscopy and diagnosis is confirmed by biopsy. There is a small subset of laryngeal malignancies that are submucosal with normal intact mucosa. This leads to difficulties in diagnosis and delay in treatment. A case of submucosal laryngeal malignancy, which had multiple negative biopsies, is reported here.

\section{CASE REPORT}

A 55-year-old male presented in our OPD with hoarse voice of 2 years' duration. He was seen 2 years earlier by an ear, nose, throat (ENT) surgeon who had made a clinical diagnosis of carcinoma larynx. Computerized tomography (CT) scan, followed by direct laryngoscopy and biopsy were done. Details of the former were not available. The latter was negative for malignancy. As his symptom persisted, he consulted another ENT surgeon who also made a clinical diagnosis of laryngeal malignancy. Once again, the biopsy was reported negative.

\footnotetext{
${ }^{1}$ Consultant, ${ }^{2}$ Consultant and Head

${ }^{1,2}$ Department of ENT and Head and Neck Surgery, Cochlear Implant Services, Medical Trust Hospital, Kochi, Kerala, India

Corresponding Author: Preethy Mary, Consultant, Department of ENT and Head and Neck Surgery, Cochlear Implant Services Medical Trust Hospital, Kochi, Kerala, India, e-mail: preethy marycharles@gmail.com
}

However, the patient's complaints worsened to stridor and a tracheostomy had to be done. A repeat CT was reported as showing an irregular enhancing mass involving the pyriform sinus and posterior pharyngeal wall of supraglottic larynx with paralysis of right vocal cord. The radiological impression was hypopharyngeal growth, most likely malignant. A subsequent biopsy, third for the patient, was also negative for cancer.

He was referred to a specialized cancer center where a third team of ENT surgeons again made a clinical diagnosis of malignancy of the larynx. Two separate biopsies in this institution were again negative. Repeat CT scan again reported the presence of a malignancy. A sixth biopsy was taken in the same institution. The patient was discharged with an appointment for radiotherapy. This biopsy was again negative.

At this point, the patient opted to go for alternative medicine. As his symptoms did not improve, he presented to our hospital in March 2012, 2 years after onset of his symptoms. He was on a tracheostomy. Both vocal cords were immobile. The glottic chink was narrow, and there was edema of the aryepiglottic fold. With a clinical diagnosis of malignancy of the larynx, he underwent his seventh biopsy in our institution. This was again reported as negative for malignancy. At this point, he was taken up for laryngofissure, and the eighth biopsy was taken from submucosal tumor-like tissue. This was reported as moderately differentiated squamous cell carcinoma.

The patient subsequently underwent wide-field (Fig. 1) laryngectomy, node clearance, primary tracheoesophageal puncture (TEP) and postoperative radiotherapy (Fig. 2). As of date, the patient is free of disease, has good speech with his TEP and has resumed work as a driver.

\section{DISCUSSION}

Diagnosis of laryngeal malignancies is usually by direct laryngoscopy and biopsy. A small proportion is submucosal with no surface abnormalities. This leads to difficulties in both diagnosis and staging. Diagnosis may be delayed in spite of direct laryngoscopic examination and biopsy. ${ }^{1}$

In our case, four different teams of ENT surgeons had made a clinical diagnosis of malignancy of the larynx. Yet confirmatory diagnosis could be made only 24 months after initial presentation, and after seven negative conventional direct laryngoscopic biopsies. 


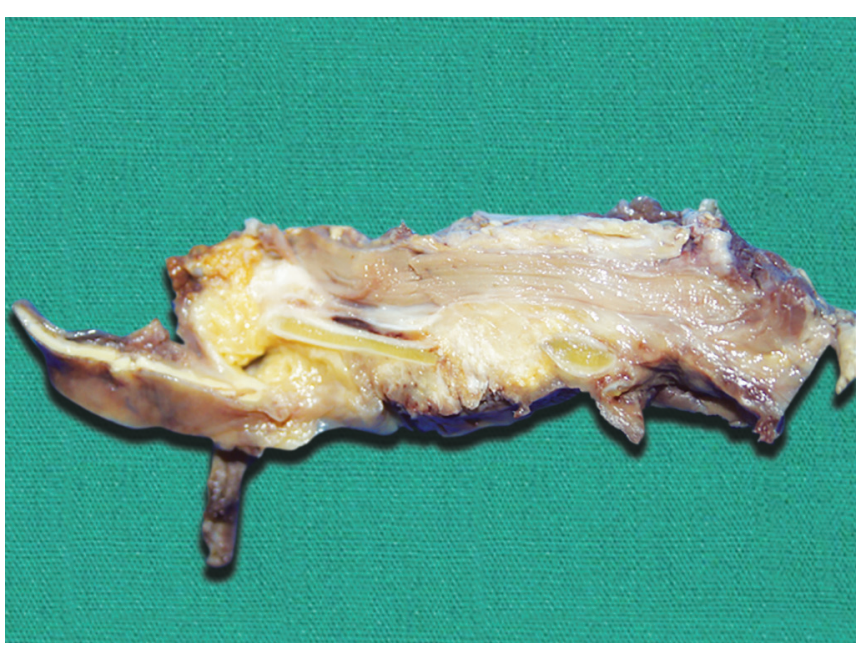

Fig. 1: Gross appearance of the laryngectomy specimen showing submucosal tumor

In a review of 51 patients with previously untreated squamous cell carcinoma of supraglottis, five $(9.8 \%)$ were found to have no abnormality on initial CT or DL scopy. These silent neoplasms present a unique problem in establishing diagnosis by routine biopsy even if CT may have detected their presence. ${ }^{2}$

Submucosal squamous cell carcinomas are reported in the tongue base and tonsils. Their etiopathogeneses are not clear. There are various theories. These include arising as a small mucosal tumor which involutes and arising from the ducts of minor salivary glands and later losing the surface connection. Differential diagnoses include both benign and malignant pathologies. ${ }^{3}$ The latter could include non-Hodgkins' lymphoma. ${ }^{4}$

Submucosal tumors may be more extensive than clinically suspected. ${ }^{5}$ A comprehensive radiological study of entirely submucosal laryngeal mass lesions was done by Saleh et al. ${ }^{6}$ Computed tomography scan was done in 24 patients with varied symptomatology. The masses were visible endoscopically as submucosal bulges in only 21 patients. Thirteen patients were eventually diagnosed as having squamous cell carcinoma, which was the primary working diagnosis following CT in 12 cases. The group of 13 carcinoma patients had a range of two to five endoscopic procedures with one to four negative biopsies and a 6 weeks' to 9 months' delay in histologic confirmation of cancer. The study concluded that CT can demonstrate the deep extent of the aerodigestive tract carcinoma more accurately than physical examination and can show mucosally inapparent disease. Hence, it should be part of the work-up in nearly all upper aerodigestive tract carcinomas. ${ }^{7}$

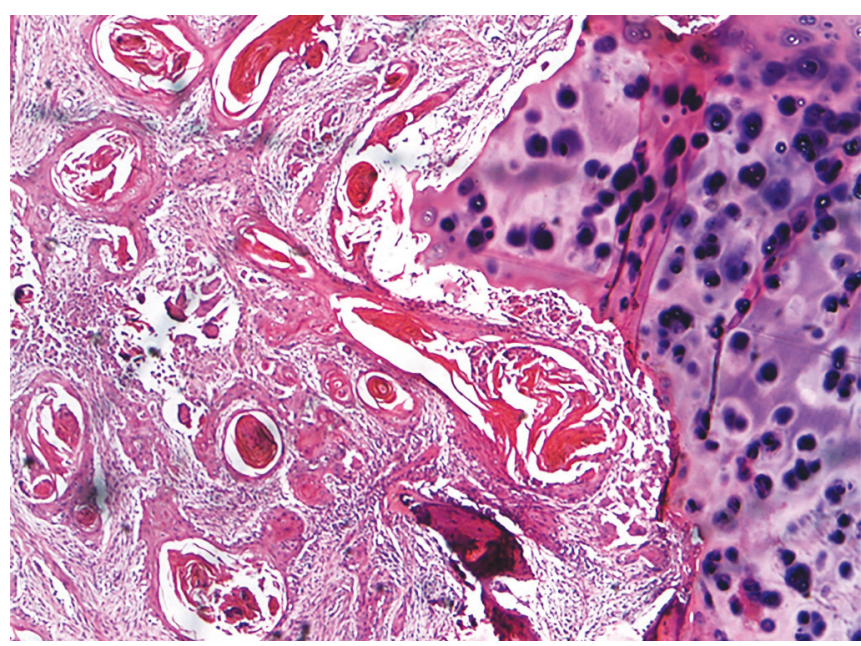

Fig. 2: Histopathology showing infiltrating moderately differentiated squamous cell carcinoma

\section{CONCLUSION}

Submucosal upper aerodigestive tract tumors are not uncommon. These are difficult to diagnose and there is a long delay between onset of symptoms and confirmation of diagnosis. When symptomatology suggests laryngeal malignancy, in spite of negative clinical findings, CT/MRI scan becomes invaluable in detecting submucosal tumors. CT scan-guided biopsy or, as in this case, an open biopsy may be needed to clinch the diagnosis.

\section{REFERENCES}

1. Myers EN, Porter GC, Jayaraj SM, Frosh AC, Patel KS. Submucosal squamous cell carcinoma of the subglottis. Otolaryngology-Head and Neck Surgery 1999;120(5): 745-746.

2. Close LG, Merkel M, Reisch J, Burns DK, Schaefer SD. Silent supraglottic carcinoma. Otolaryngology-Head and Neck Surgery 1988;99(3):286-295.

3. Friedman AD, Burns JA, Lutch MJ, Zeitels SM. Submucosal neoplasms of the laryngeal introitus. J Laryngol Otol 2012;126(7):706-713.

4. Franzen A, Kurrer MO. Malignant lymphoma of the larynx: a case report and review of the literature. Laryngo-rhino-otol 2000;79(10):579-583.

5. Hermans R, editor. Head and neck cancer imaging. Springer; 2012. p. 88.

6. Saleh EM, Mancuso AA, Stringer SP. CT of submucosal and occult laryngeal masses. J Computer-assisted Tomography 1992;16(1):87-93.

7. Mancuso AA, Hanafee WN. Elusive head and neck carcinomas beneath intact mucosa. The Laryngoscope 1983; 93(2):133-139. 